\title{
28 Resarch Soure on \\ The Effect of COVID-19 Infection on the Aerobic Capacity of Professional Soccer Players.
}

Koulla Parpa ( $\square$ kparpa@uclan.ac.uk)

University of Central Lancashire - Cyprus Campus

Marcos Michaelides

University of Central Lancashire - Cyprus Campus

Research Article

Keywords: COVID-19, infection, aerobic capacity, professional soccer players, SARS-CoV-2

Posted Date: November 15th, 2021

DOl: https://doi.org/10.21203/rs.3.rs-1034685/v1

License: @ (1) This work is licensed under a Creative Commons Attribution 4.0 International License. Read Full License 


\section{Abstract}

This investigation assessed the effect of COVID-19 on the aerobic capacity of professional soccer players who have tested positive. Twenty-one division- 1 elite soccer players (age 24.24 \pm 5.75 years, height $178.21 \pm 5.44 \mathrm{~cm}$, weight $74.12 \pm 5.21 \mathrm{~kg}$ ) participated in this study. This observational study compared the same players' aerobic capacity pre-, and 60-days post COVID-19 recovery. The statistical analysis demonstrated that the infected players had significantly lower V02max values $\left[\mathrm{t}_{(20)}=5.17, \mathrm{p}<0.01, \mathrm{~d}=0.613\right.$ (medium effect)], and significantly lower VO2 values at $R C\left[t_{(20)}=2.97, p<0.05, d=0.39\right.$ (small effect)] after recovery. Furthermore, results indicated a significantly lower running time $(R T)$ on the treadmill $\left[t_{(20)}=4.84, p<0.01, d=0.46\right.$ (small effect)] when compared to the results that were obtained before they got infected. In addition, velocity at V02max ( $\mathrm{V} V 02_{\mathrm{max}}$ ) was significantly lower $\left[t_{(20)}=2.34, p<0.05, d=0.41\right.$ (small effect) $]$ and the heart rate values at $L T\left[t_{(20)}=-2.79, p<0.01, d=0.55\right.$ (medium effect) $]$ and $R C\left[t_{(20)}=-3.72, p<0.01, d=0.52\right.$ (medium effect)] were significantly higher post recovery. The aforementioned findings indicate that post COVID-19 soccer players may not reach full recovery at two months. Therefore, our results should alert practitioners and fitness coaches of the risk of longer-duration silent symptoms even in athletes that experience mild to moderate manifestations.

\section{Introduction}

Coronavirus, a highly infectious disease currently termed severe acute respiratory syndrome coronavirus 2 (SARSCoV-2), is generally accompanied by mild to moderate manifestations [1]. However, a small proportion of patients develops a severe respiratory illness that may lead to death in some cases [1]. The lungs are the organs primarily affected by COVID19 as the virus accesses host cells via the enzyme ACE2 (angiotensin-converting enzyme 2), which is most abundant in alveolar (Type II) cells of the lungs [2]. Once the spike glycoproteins of SARS-CoV-2 connect to ACE2, the virus enters the host cell [2]. Thus, even though the lungs are the most affected organs by COVID-19, the virus can spread to other organs and infect ACE2-expressing cells at local sites, causing multi-organ problems [2]. Considering that ACE2 receptors are highly expressed in the heart, that may explain the acute myocardial injuries that have been noted as complications in patients infected with SARS-CoV-2 [2]. It is worth noting that the exact pathophysiology of COVID-19 remains unclear, and cardiac injury is reported to result from direct or indirect mechanisms [3].

The infection rate among professional soccer players is consistent with that of the general population [4], and most of the time, COVID-19 positive athletes are asymptomatic. However, they may experience mild to moderate symptoms such as fever, cough, loss of taste or smell, headache, aches, muscle pain, sore throat, and tiredness $[4,5,6]$. Less common and more severe symptoms include shortness of breath, pain and pressure in the chest, or pneumonia [5]. It has been recommended that symptomatic athletes with moderate manifestations should rest from exercise during the symptomatic phase and for at least 14 days after the complete resolution of symptoms, while asymptomatic patients should not resume physical activity for at least 14 days after diagnosis [5]. Conclusively, COVID-19 positive professional soccer players find themselves in a unique situation in which they are not only obliged to be self-isolated but also, to abstain from any form of physical activity for at least 14 days after diagnosis.

Positive COVID-19 soccer players could potentially have even higher psychological and physiological strain than that reported during quarantine periods $[7,8]$. Notably, the lockdown alone has been indicated to evoke a negative effect on mental wellbeing [9] and emotional status, with a great proportion of individuals experiencing psychosocial and emotional disorders (7). Not surprisingly, an increase in sedentary behavior during leisure time 
was associated with poorer physical health, mental health, and subjective vitality [10]. In addition to the psychological distress, a multilingual online survey of 5056 participants affirms that COVID-19 confinement led to impaired sleep quality that was related to sleep disturbances, daytime dysfunction, the use of sleep medications, and sleep latency (8). Additionally, although home-based training during lockdown effectively improved aerobic fitness [11,12], athletes' competitive power levels were not maintained [11]. Therefore, a period of complete inactivity is expected to have more significant reductions in physical conditioning. Research affirms that detraining induces a rapid decline in aerobic capacity, resulting in an increased heart rate for any given workload [13].

Furthermore, research demonstrated that even a short period of inactivity might have a significant detraining effect. In particular, 2-weeks of inactivity caused a marked reduction in endurance capacity and repeated sprint ability in semi-professional soccer players [14]. Similarly, top-level road cyclists have been shown to produce significant reductions in aerobic capacity and power output after five weeks of detraining [15].

It is unknown whether soccer players who have been infected and recovered have residual cardiorespiratory complications, as there are no clinical data to indicate that. However, earlier reports in SARS patients (2003 outbreak) suggest the possibility of cardiorespiratory impairments in athletes even 24 months after SARS onset [32]. Furthermore, considering that full-length genome sequencing has shown a close association between SARSCoV-2 and SARS-CoV, monitoring for these impairments is paramount [16]. Conclusively, the determination of the detrimental effects of SARS-CoV-2 on elite soccer players' cardiorespiratory system is of utmost importance. Therefore, the aim of this study was to assess the effect of COVID-19 on the aerobic capacity of professional soccer players who have tested positive.

\section{Materials And Methods}

\section{Subjects}

Twenty-one division-1 elite soccer players (age 24.24 \pm 5.75 years, height $178.21 \pm 5.44 \mathrm{~cm}$, weight $74.12 \pm 5.21 \mathrm{~kg}$ ) participated in this study. All the players were tested at the end of April (pre-testing) as part of their teams' assessment (Table 1). 
Table 1

Testing Timeline

\begin{tabular}{|c|c|c|c|c|c|c|c|c|c|c|c|}
\hline 2021 & Jan & Feb. & & March & April & & May & June & & July & August \\
\hline $\begin{array}{l}\text { Second } \\
\text { Lockdown }\end{array}$ & $\begin{array}{l}31 \\
\text { days }\end{array}$ & & & & & & & & & & \\
\hline $\begin{array}{l}\text { Official } \\
\text { Games }\end{array}$ & & $\begin{array}{l}1-15 \\
\text { days }\end{array}$ & $\begin{array}{l}16- \\
28 \\
\text { days }\end{array}$ & $\begin{array}{l}31 \\
\text { days }\end{array}$ & $\begin{array}{l}1-15 \\
\text { days }\end{array}$ & & & & & & \\
\hline Pre-testing & & & & & & $\begin{array}{l}16- \\
30 \\
\text { days }\end{array}$ & & & & & \\
\hline $\begin{array}{l}\text { COVID-19 } \\
\text { positive } \\
\text { recruitment }\end{array}$ & & & & & & & $\begin{array}{l}31 \\
\text { days }\end{array}$ & $\begin{array}{l}1-15 \\
\text { days }\end{array}$ & & & \\
\hline $\begin{array}{l}\text { 2-weeks no } \\
\text { training }\end{array}$ & & & & & & & & & $\begin{array}{l}16- \\
30 \\
\text { days }\end{array}$ & & \\
\hline $\begin{array}{l}\text { Adaptation } \\
\text { program }\end{array}$ & & & & & & & & & & $\begin{array}{l}31 \\
\text { days }\end{array}$ & $\begin{array}{l}1-15 \\
\text { days }\end{array}$ \\
\hline $\begin{array}{l}\text { Post- } \\
\text { testing }\end{array}$ & & & & & & & & & & & $\begin{array}{l}16- \\
30 \\
\text { days }\end{array}$ \\
\hline
\end{tabular}

Those who underwent the initial testing and have tested positive for COVID-19 during the following months were recruited for this study. However, not everyone that was initially recruited participated in the study. Asymptomatic players were excluded, and only those that reported two or more mild to moderate symptoms of body discomfort were included in the study. Of note, none of the athletes have had COVID-19 severe enough to be hospitalized. Furthermore, players who have tested positive after being vaccinated were also excluded from the study. Finally, goalkeepers were excluded from the study as they did not follow the same re-training and adaptation program to the in-field players after they recovered. Conclusively, those players who met the inclusion criteria were tested after 60 days of their return to normal activities. As reported by the team's staff and medical group, prior to the resumption of vigorous training, the players had a minimum of two consecutive negative PCR tests and a confirmed IgM negative test in addition to the specific health evaluation that included a cardiology assessment. Furthermore, before the post-testing, the players followed a 2-week re-training program based on the safe return to sport activities guidelines [17]. In addition, they followed a 10-days specific adaptation program and a 20-days game adaptation program based on the guidelines [17] (Table 2). 
Table 2

Phases: Return to training and games following COVID-19 infection

\begin{tabular}{|c|c|c|c|}
\hline Phase & Exercises & Sessions & Duration \\
\hline \multirow[t]{4}{*}{ Re-training } & Individual football specific exercises & $\begin{array}{l}1 \text { per day (max } \\
45-60 \text { min) }\end{array}$ & 14 Days \\
\hline & $\begin{array}{l}\text { Focus on aerobic conditioning without strength and explosive } \\
\text { power training }\end{array}$ & & \\
\hline & All exercises performed at low to moderate intensity & & \\
\hline & Attention to load distribution & & \\
\hline \multirow[t]{3}{*}{$\begin{array}{l}\text { Specific } \\
\text { Adaptation }\end{array}$} & Football specific training exercises in a group & $\begin{array}{l}1 \text { per day (max } \\
75 \mathrm{~min})\end{array}$ & 10 Days \\
\hline & $\begin{array}{l}\text { Gradual increase of session training intensity with } \\
\text { appropriate recovery time }\end{array}$ & & \\
\hline & Position specific training activities & & \\
\hline \multirow[t]{5}{*}{$\begin{array}{l}\text { Game } \\
\text { Adaptation }\end{array}$} & $\begin{array}{l}\text { Introduction to high-speed movements such as sprinting, } \\
\text { kicking and changes of direction }\end{array}$ & $\begin{array}{l}1 \text { per day (max } \\
75-90 \text { min) }\end{array}$ & 20 Days \\
\hline & Introduction to match play drills & & \\
\hline & Friendly games with attention to individual minutes played & & \\
\hline & $\begin{array}{l}\text { Progressive increase in participation minutes during friendly } \\
\text { games }\end{array}$ & & \\
\hline & $\begin{array}{l}\text { Application of specific recovery protocols post games and the } \\
\text { day after }\end{array}$ & & \\
\hline
\end{tabular}

Thus, this observational study compared the same players' aerobic capacity measurements that were obtained at the end of April following the 2 nd lockdown to those obtained 60-days post COVID-19 recovery. All the participants had medical clearance and a negative COVID-19 polymerase chain reaction (PCR) test within 48-72 hours before the testing despite recovering from COVID. Players' participation in this study was completely voluntary, and each player was briefed on the procedures before they signed an institutionally approved written informed consent form. The study was carried out in accordance with the Declaration of Helsinki and was approved by the University's ethics committee board and the National Committee on Bioethics. The researchers were required to wear a face mask, face shield, gown, and gloves during data collection and adhered to the guidelines for patients and testing personnel during aerosolizing procedures as indicated by the Centers for Disease Control and Prevention [18].

\section{Procedures}

Anthropometric measurements were recorded using a wall stadiometer (Leicester; Tanita, Tokyo, Japan) to measure the players' stature and a leg-to-leg bioelectrical impedance analyzer (BC418MA; Tanita) to measure body composition.

\section{Cardiopulmonary exercise testing}

The players completed an incremental maximal cardiopulmonary exercise testing (CPET) until they reached exhaustion on a treadmill (h/p/Cosmos Quasar med, H-P-Cosmos Sports \& Medical GmbH, Nussdorf-Traunstein, 
Germany). A breath-by-breath analysis was performed on the Cosmed Quark CPET (Rome, Italy) system. Laboratory conditions were kept constant, with the temperature at $22 \pm 1^{\circ} \mathrm{C}$ and relative humidity at $50 \%$. The players were tested utilizing the modified Heck incremental maximal protocol, which was previously validated for its reliability to test soccer players [19]. The test came to an end when the participant reached volitional fatigue or when there was no variation among the $\mathrm{VO} 2$ levels while the workload increased. The VO2max was detected after having the results filtered to identify the highest value for an average of 10 seconds.

\section{Determination of Ventilatory Threshold and Respiratory Compensation Point}

The ventilatory threshold (VT) and respiratory compensation point (RC) were determined using different criteria. The VT was determined through the V-Slope method, the point at which the increase in the rate of elimination of carbon dioxide ( $\mathrm{V} \mathrm{CO2}$ ) is greater than the increase in $\mathrm{V}$ 02. The VT point was verified at the nadir of the VE/V 02 curve. The RC point was determined at the nadir of the VE/V CO2 curve [20, 21].

\section{Statistical Analyses}

SPSS 26.0 for Windows (SPSS Inc., Chicago) was used for analyzing the results. Normality and homogeneity of variances were examined and verified using the Shapiro-Wilk and the Brown and Forsythe tests, respectively. The mean and SD were calculated for all parameters. Paired t-tests were used to identify the differences between the pre-and post-measurements in aerobic capacity. Cohen's $d$ was calculated to determine the effect size. Effect sizes were interpreted as follows: small (0.2-0.4), medium (0.5-0.7), and large (0.8-1.4) [22]. For all statistical analyses, significance was accepted at $\mathrm{p}<0.05$.

\section{Results}

Results demonstrated that the infected players had significantly lower V02max values $\left[t_{(20)}=5.17, p<0.01, d=0.613\right.$ (medium effect)], and significantly lower V02 values at $R C\left[t_{(20)}=2.97, p<0.05, d=0.39\right.$ (small effect)] 60 days after recovery (Table 3, Fig. 2). At the same time no significant difference was demonstrated in the VO2 values at LT following COVID-19 recovery. Furthermore, results indicated a significantly lower running time (RT) on the treadmill $\left[t_{(20)}=4.84, p<0.01, d=0.46\right.$ (small effect)], when compared to the results that were obtained before they got infected (Table 3). In addition, the running velocities at $L T\left({ }_{v} L T\right)$ and $R C\left({ }_{v} R C\right)$ were not significantly different post-COVID-19 recovery while the velocity at $\mathrm{VO} 2 \mathrm{max}\left(\mathrm{V} V \mathrm{~V} 2_{\max }\right)$ was significantly lower $\left[\mathrm{t}_{(20)}=2.34, \mathrm{p}<0.05, \mathrm{~d}=0.41\right.$ (small effect)] (Table 4, Fig. 3). Lastly, peak heart rate values remained unchanged while heart rate values at $L T\left[t_{(20)}=-2.79\right.$, $\mathrm{p}<0.01, d=0.55$ (medium effect)] and $\mathrm{RC}\left[\mathrm{t}_{(20)}=-3.72, \mathrm{p}<0.01, \mathrm{~d}=0.52\right.$ (medium effect)] were significantly higher post COVID-19 recovery compared to pre COVID infection (Table 5, Fig. 1). 
Table 3

V02max, V02 at lactate threshold (LT), VO2 at respiratory compensation point (RC), and run time (RT)

\begin{tabular}{|llll|}
\hline & & $\begin{array}{l}\text { Pre-COVID-19 } \\
\text { Infection }\end{array}$ & $\begin{array}{l}\text { Post-COVID-19 } \\
\text { Recovery }\end{array}$ \\
\hline & $\mathrm{n}$ & Mean $\pm \mathrm{SD}$ & Mean $\pm \mathrm{SD}$ \\
\hline $\mathrm{VO} 2 \mathrm{max}(\mathrm{ml} / \mathrm{kg} / \mathrm{min})$ & 21 & $57.35 \pm 4.55$ & $54.34 \pm 5.24 * *$ \\
\hline VO2 at LT $(\mathrm{ml} / \mathrm{kg} / \mathrm{min})$ & 21 & $37.12 \pm 6.40$ & $36.89 \pm 5.18$ \\
\hline VO2 at $\mathrm{RC}(\mathrm{ml} / \mathrm{kg} / \mathrm{min})$ & 21 & $49.80 \pm 6.10$ & $47.47 \pm 5.73^{*}$ \\
\hline $\mathrm{RT}(\mathrm{min})$ & 21 & $17.54 \pm 2.21$ & $16.56 \pm 2.05^{\star *}$ \\
\hline${ }^{*} \mathrm{p}<0.05,{ }^{* *} \mathrm{p}<0.01$. & & & \\
\hline
\end{tabular}

Table 4

Running velocities at VO2max, LT and RC

\begin{tabular}{|llll|}
\hline & $\begin{array}{l}\text { Pre-COVID-19 } \\
\text { Infection }\end{array}$ & $\begin{array}{l}\text { Post-COVID-19 } \\
\text { Recovery }\end{array}$ \\
\hline & $\mathrm{n}$ & Mean $\pm \mathrm{SD}$ & Mean $\pm \mathrm{SD}$ \\
\hline $\mathrm{vVO} 2 \mathrm{max}\left(\mathrm{km} \cdot \mathrm{h}^{-1}\right)$ & 21 & $17.43 \pm 1.43$ & $16.86 \pm 1.35^{\star}$ \\
\hline $\mathrm{v}^{\mathrm{TL}}\left(\mathrm{km} \cdot \mathrm{h}^{-1}\right)$ & 21 & $10.19 \pm 1.66$ & $10.19 \pm 1.40$ \\
\hline $\mathrm{V} R C\left(\mathrm{~km} \cdot \mathrm{h}^{-1}\right)$ & 21 & $13.90 \pm 1.73$ & $13.90 \pm 1.61$ \\
\hline${ }^{*} \mathrm{p}<0.05,{ }^{* *} \mathrm{p}<0.01$. & & & \\
\hline
\end{tabular}

Table 5

Heart rate at $L T\left(\mathrm{HR}_{\mathrm{LT}}\right)$, heart rate at $\mathrm{RC}\left(\mathrm{HR}_{\mathrm{RC}}\right)$ and heart rate max $\left(\mathrm{HR}_{\max }\right)$

\begin{tabular}{|c|c|c|c|}
\hline & & $\begin{array}{l}\text { Pre-COVID-19 } \\
\text { Infection }\end{array}$ & $\begin{array}{l}\text { Post-COVID-19 } \\
\text { Recovery }\end{array}$ \\
\hline & $\mathrm{n}$ & Mean \pm SD & Mean \pm SD \\
\hline $\mathrm{HR}_{\max }\left(\right.$ beats $\cdot \mathrm{min}^{-1}$ ) & 21 & $190.14 \pm 7.93$ & $191.48 \pm 7.67$ \\
\hline $\mathrm{HR}_{\mathrm{LT}}$ (beats·min ${ }^{-1}$ ) & 21 & $149.90 \pm 16.62$ & $158.14 \pm 12.97^{\star \star *}$ \\
\hline $\mathrm{HR}_{\mathrm{RC}}\left(\right.$ beats $\cdot \mathrm{min}^{-1}$ ) & 21 & $174.52 \pm 9.32$ & $179.57 \pm 10.07 * *$ \\
\hline${ }^{*} \mathrm{p}<0.05, * * \mathrm{p}<0.01$. & & & \\
\hline
\end{tabular}




\section{Discussion}

To the best of our knowledge, this is the first study to examine the effect of COVID-19 infection on the aerobic capacity of professional soccer players. Considering that the average intensity in a 90-min soccer game is close to that of the lactate threshold [23], it is evident that aerobic performance in soccer is not only dependent on VO2max but also on lactate thresholds and the associated running velocities [24]. Research affirms that enhancement of aerobic capacity leads to improved soccer performance, as it increases the total distance covered by the players, the level of work intensity [34] as well as the number of sprints during competitive games [25]. This study demonstrated a significant reduction in VO2max and running times on the treadmill about 60 days post COVID-19 recovery. Furthermore, the VO2 at RC was significantly lower while the VO2 at LT was reduced but not significantly. Studies highlight the importance of using thresholds to indicate and monitor the improvements in aerobic performance indices during each period of a typical soccer season [26]. More specifically, research indicated that 8week preseason training caused significant increases in the RC point and VT [26]. Furthermore, research indicated that RC point is inversely correlated with hypoxic ventilatory response and that 40 to $50 \%$ of the variance of RC is accounted for by hypoxic ventilatory response and delta slope (rate of lactic acid increase during exercise) [21]. The reduction in the $\mathrm{RC}$ point in this study may indicate an increased hypoxic ventilatory response which could be compensated by the cardiovascular system in soccer players. While "silent" hypoxemia has been reported in COVID19 [27], it is unclear if it persists after recovery in athletes with mild or moderate manifestations. Additionally, prior to the RC point, the cardiorespiratory challenge was not associated with the expiration of the amount of $\mathrm{CO} 2$, and the need for oxygen was met primarily through the increase in tidal volume and not the respiratory rate. While that is true for VT, the RC point is associated with hyperventilation, that is, the loss of linearity in a plot between VE and $\checkmark$ CO2. In this study, the earlier occurrence of the RC point, which is associated with hyperventilation due to the failure of bicarbonate buffering and the consecutive fall in blood $\mathrm{pH}$ [28], should be taken into consideration as the significant reductions in aerobic performance indices infer a decline in physical performance during the competitive games of the players. Concurrently, these reductions cannot be solely attributed to the detraining period as the athletes followed a 2-week re-training program, a 10-days specific adaptation program, and a 20-days game adaptation program following their recovery (Table 1). Therefore, our findings may raise essential concerns regarding the players' preparedness as we demonstrate that the players have reduced exercise capacity even 60 days post COVID-19 recovery.

Despite the significant reductions in V02max, RT, and VO2 at RC, the velocities at both TL and RC remained the same. With regards to the velocities, the only significant reduction was indicated on $\mathrm{V} V \mathrm{O} 2 \mathrm{max}$. Research demonstrated that running speeds at maximum lactate steady state are directly related to the ability to use oxygen and, subsequently, to enhance metabolite removal [29]. Additionally, the velocity at which VO2max is reached ( $\mathrm{V}$ O2max) in soccer has positively correlated with the distance covered and the running intensity of professional players [30]. Even though $\vee$ VO2max was significantly lower (from 17.43 to $16.86 \mathrm{~km} / \mathrm{h}$ ) following COVID-19 recovery, similar running velocities were reported by others after the preseason training [26].

With respect to heart rate changes, this study demonstrated significantly higher heart rates at both LT and RC while maximal HR was increased but not significantly following COVID-19 recovery. Considering the reduction of RC point, it could be assumed that increased heart rates at RC and LT may be associated with an increased cardiovascular response due to hypoxemia [27]. While increases in submaximal and maximal heart rates have been associated with detraining, the mechanisms involved in the elevation of heart rates at LT and RC in our study need further investigation. To date, there are no published studies on the assessment of maximal functional capacity 
using direct measurement of oxygen uptake in athletes post COVID-19. A study of SARS survivors six months after discharge indicated that $75 \%$ of the survivors had abnormal tests, out of which $43 \%$ had reduced work due to deconditioning, $19 \%$ had cardiovascular limitations, and $6 \%$ had pulmonary limitations [31]. Another study reported that survivors of ALI (acute lung injury) experience frequent and often distressing pulmonary and psychological symptoms long after their lung injury [32].

To sum up, all the aforementioned findings indicate that post COVID-19 soccer players may not reach full recovery at two months; therefore, a more detailed evaluation should be conducted before they return to official games. Our results should alert practitioners, fitness coaches, and soccer players of the risk of longer-duration silent symptoms even in athletes that experience mild to moderate manifestations. Practitioners need to be able to adjust the training intensities to gradually enhance the fitness levels of the infected players. Consideration should be given not only to the VO2max and running time on the treadmill but also to other performance indices such as the VT, RC, heart rates, and running velocities at those thresholds. Furthermore, it is suggested that maximal cardiorespiratory testing should be utilized to assess the aerobic capacity of the players before the official games. Since there is the possibility that athletes who contracted COVID-19 have late cardiorespiratory complications, the cardiorespiratory testing can help differentiate low conditioning from cardiorespiratory inefficiency.

\section{Conclusions}

This study demonstrated that a successful return to play necessitates the development of more specific protocols for the safe return of athletes that were infected even if they experienced mild to moderate manifestations. Ideally, those protocols should be determined on a case-by-case basis considering the severity of COVID-19, period of inactivity, and pre-infection fitness level. In addition, consideration should be given to the psychological status [7], playing position [33], age, and division in which each player participates, as all the above will contribute to the safe and successful return to training and competition. Lastly, further investigation is needed using GPS technology to evaluate to what extend the external load of the infected players was affected.

\section{Declarations}

Author contributions: KP and MM contributed equally to the design of the work; the data acquisition, analysis, interpretation of data and writing of the manuscript. Both KP and MM approved the submitted version.

Conflict of interest: The authors declare no competing interests.

\section{References}

1. WHO. Coronavirus disease (COVID-19). World Health Organization. https://www.who.int/healthtopics/coronavirus\#tab=tab_1. (2021).

2. Ni, W. et al. Role of angiotensin-converting enzyme 2 (ACE2) in COVID-19. Crit Care. 24, 422 (2020)

3. Kim, C.W., \& Aronow, W. S. COVID-19, cardiovascular diseases and cardiac troponins. Future Cardiol. 3, 10.2217/fca-2021-0054 (2021).

4. Schumacher, Y. O. et al. Resuming professional football (soccer) during the COVID-19 pandemic in a country with high infection rates: a prospective cohort study. British Journal of Sports Medicine. 55, 1092-1098 (2021).

5. Colombo, C. S. S. S. et al. Position Statement on Post-COVID-19 Cardiovascular Preparticipation Screening: Guidance for Returning to Physical Exercise and Sports - 2020. Arq Bras Cardiol. 116, 1213-26 (2021). 
6. Lopes, L. R. et al. Repercussions of the COVID-19 pandemic on athletes: a crosssectional study. Biol Sport. 38, 703-711 (2021).

7. Ammar, A. et al. Effects of home confinement on mental health and lifestyle behaviours during the COVID-19 outbreak: insights from the ECLB-COVID19 multicentre study. Biol Sport. 38, 9-21 (2021).

8. Trabelsi, K. et al. Globally altered sleep patterns and physical activity levels by confinement in 5056 individuals: ECLB COVID-19 international online survey. Biol Sport. 38, 495-506 (2021).

9. Richardson, D. L., Clarke, N. D., Broom, D. R., Tallis, J., \& Duncan, M. J. Life after lockdown: The role of sport, exercise and physical activity in ameliorating the mental health implications of COVID-19 restrictions. J Sports Sci. 39, 2144-2146 (2021).

10. Cheval, B. el al. Relationships between changes in self-reported physical activity, sedentary behaviour and health during the coronavirus (COVID-19) pandemic in France and Switzerland. J Sports Sci. 39, 699-704 (2021).

11. Rampinini, E., Donghi, F., Martin, M., Bosio, A., Riggio, M., \& Maffiuletti, N. A. Impact of COVID-19 Lockdown on Serie A Soccer Players' Physical Qualities. Int J Sports Med. 42, 917-923 (2021).

12. Parpa, K., \& Michaelides, M. The impact of COVID-19 lockdown on professional soccer players' body composition and physical fitness. Biol Sport. 38, 733-740 (2021).

13. Mujika, I., \& Padilla, S. Detraining: loss of training-induced physiological and performance adaptations. Part I: short term insufficient training stimulus. Sports Med. 30, 79-87 (2020).

14. Joo, C. H. The effects of short-term detraining and re-training on physical fitness in elite soccer players. PLoS One. 13, e0196212 (2018).

15. Maldonado-Martín, S., Cámara, J., James, D. V. B, Fernández-López, J. R., Artetxe-Gezuraga, X. Effects of longterm training cessation in young top-level road cyclists. J Sports Sci. 35, 1396-1401 (2017).

16. Ngai, J. C. et al. The long-term impact of severe acute respiratory syndrome on pulmonary function, exercise capacity and health status. Respirology. 15, 543-50 (2021).

17. Aspetar Clinical Guidelines : Safe Return to Sport during the COVID-19 Pandemic (2020).

18. Centers for Disease Control and Prevention Interim Infection Prevention and Control Recommendations for Healthcare Personnel During the Coronavirus Disease 2019 (COVID-19) Pandemic. https://www.cdc. gov/coronavirus/2019-ncov/hcp/ infection-control-recommendations (2021).

19. Santos-Silva, P. R., Fonseca, A.J., Castro, A. W., Greve, J. M., \& Hernandez, A. J. Reproducibility of maximum aerobic power (VO2max) among soccer players using a modified heck protocol. Clinics (Sao Paulo). 62, 391-6 (2007).

20. Beaver, W., Wasserman, K., Whipp, B. A new method for detecting anaerobic threshold by gas exchange. J App/ Physiol. 60, 2020-2027 (1986).

21. Takano, N. Respiratory compensation point during incremental exercise as related to hypoxic ventilatory chemosensitivity and lactate increase in man. Jpn J Physiol. 50, 449-455 (2020).

22. McMaster, D. T., Gill, N., Cronin, J., \& McGuigan, M. The development, retention and decay rates of strength and power in elite rugby union, rugby league and American football: a systematic review. Sports Med. 43, 367-84 (2013).

23. Stølen, T., Chamari, K., Castagna, C., \& Wisløff, U. Physiology of soccer: an update. Sports Med. 35, 501-36 (2005). 
24. Reilly, T., Bangsbo, J., \& Franks, A. Anthropometric and physiological predispositions for elite soccer. J Sports Sci. 18, 669-83 (2000).

25. Helgerud, J., Engen, L. C., Wisloff, U., \& Hoff, J. Aerobic endurance training improves soccer performance. Med Sci Sports Exerc. 33, 1925-1931 (2001).

26. Michaelides, M. A., Parpa, K. M, \& Zacharia, A. I. Effects of an 8-Week Pre-seasonal Training on the Aerobic Fitness of Professional Soccer Players. J Strength Cond Res. 35, 2783-2789 (2021).

27. Bickler, P. E., Feiner, J. R., Lipnick, M. S., \& McKleroy, W. "Silent" Presentation of Hypoxemia and Cardiorespiratory Compensation in COVID-19. Anesthesiology. 134, 262-269 (2021).

28. Meyer, T. et al. Is lactic acidosis a cause of exercise induced hyperventilation at the respiratory compensation point? British Journal of Sports Medicine. 2004;38:622-625.

29. Hoff J. Training and testing physical capacities for elite soccer players. J Sports Sci. 23, 573-82 (2005).

30. Rampinini, E. et al. Validity of simple field tests as indicators of match-related physical performance in top-level professional soccer players. Int J Sports Med. 28, 228-35 (2007).

31. Chan, V. L., Lam, J. Y., Leung, W. S., Lin, A. W., \& Chu, C. M. Exercise Limitation in Survivors of Severe Acute Respiratory Syndrome (SARS). Chest. 126, 737S (2004).

32. Weinert, C. R., Gross, C. R., Kangas, J. R., Bury, C. L., \& Marinelli, W. A. Health-related quality of life after acute lung injury. Am J Respir Crit Care Med. 156, 1120-8 (1997).

33. Hasan, U. Ch., Silva, R., \& Clemente, F. M. Weekly variations of biomechanical load variables in professional soccer players: comparisons between playing positions. Hum Mov. 22, 19-34 (2021).

34. Krustrup, P., Mohr., M., Ellingsgaard, H., \& Bangsbo, J. Physical demands during an elite female soccer game: importance of training status. Med Sci Sports Exerc. 37, 1242-8 (2005).

\section{Figures}




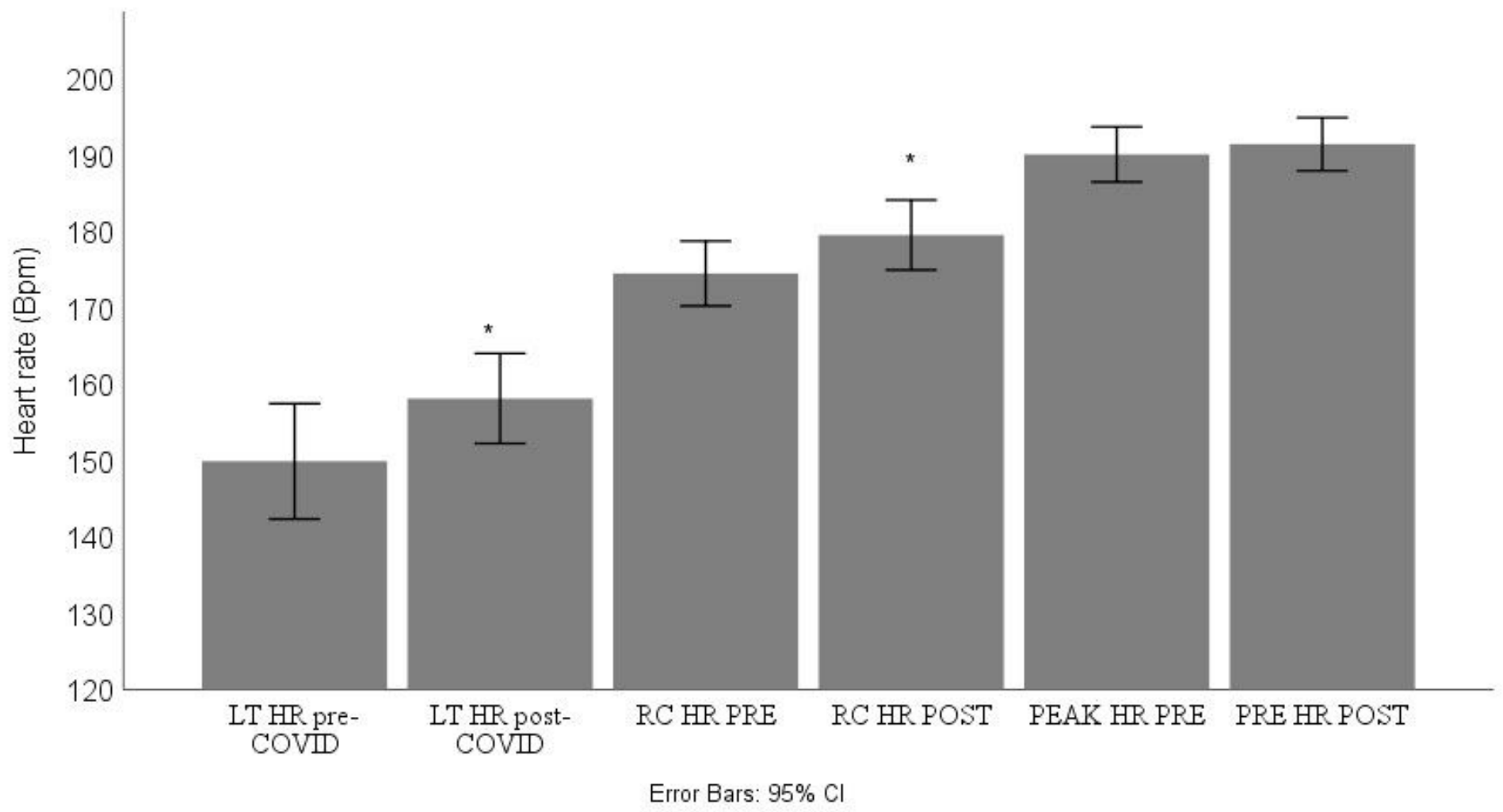

Figure 1

Heart rate at LT, heart rate at RC, and heart rate max pre- and post-COVID-19 infection * $p<0.01$ 


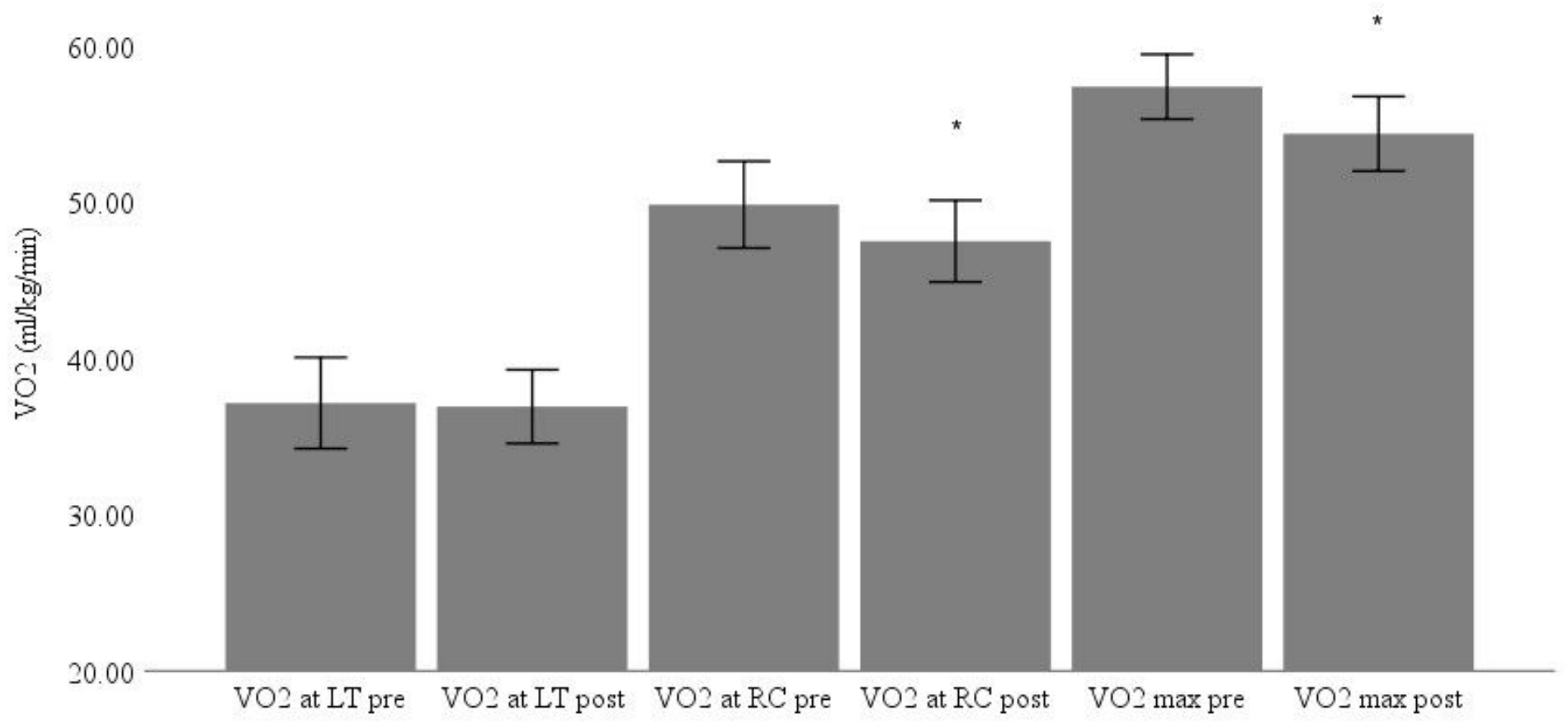

Error Bars: $95 \% \mathrm{Cl}$

Figure 2

V02max, V02 at lactate threshold (LT), VO2 at respiratory compensation point (RC) pre-and post-COVID-19 infection ${ }^{*} \mathrm{p}<0.01$ 


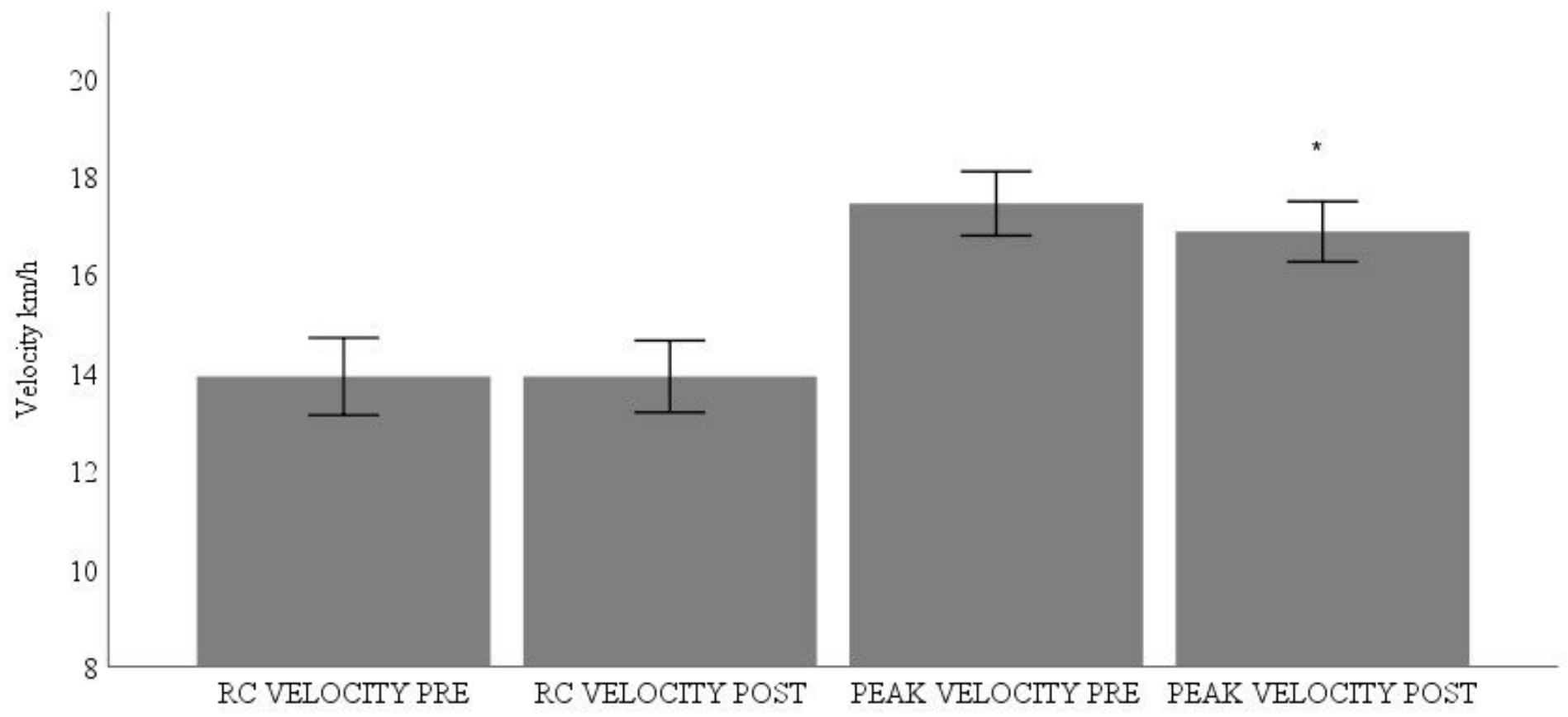

Error Bars: $95 \% \mathrm{Cl}$

\section{Figure 3}

Running velocities at $\mathrm{RC}$ and Peak pre-and post-COVID-19 infection ${ }^{*} \mathrm{p}<0.01$ 